\title{
Effect of Cartilage Porosity on Synovial Joint: Boosted Lubrication
}

\author{
${ }^{1}$ Kapil Shekhar, ${ }^{2}$ A. P. Tyagi \\ Department of Mathematics, Faculty of Science, \\ Dayalbagh Educational Institute (Deemed University), \\ Dayalbagh, Agra - 282005, Uttar Pradesh, India \\ kapil.shekhar@yahoo.com
}

\begin{abstract}
An analytical solution of load bearing characteristics in a squeeze film model for normal human knee joint is obtained. The cartilage surfaces are taken to be porous and the viscosity variation of synovial fluid with hyaluronate concentration is also considered. It is found that the effect of permeability in the normal direction has a favorable effect on the load capacity as well as on the squeeze time.
\end{abstract}

Keywords - Reynolds equation, Viscosity variation, Squeeze film lubrication, Load capacity, Squeeze time.

\section{INTRODUCTION}

The study of mechanism of synovial joints has recently become an active area of scientific research. The human synovial joint (Figure 1) is a dynamically loaded bearing which employs articular cartilage as the bearing and synovial fluid as the lubricant. Once a fluid film is generated, squeeze film action is capable of providing considerable protection to the cartilage surface. The loaded bearing synovial joints of the human body are the shoulder, hip, knee, and ankle joints. Synovial fluid is a clear viscous fluid, a dialysate of plasma containing muco-polysaccharides. Synovial fluid usually exhibits a non-Newtonian shear thinning behavior. However, under high shear rates, the viscosity of synovial fluid approaches a constant value not much higher than that of water (Cooke et al. [1]). Therefore, a Newtonian lubricant model has often used for synovial fluid in lubrication modeling (Dowson et al. [2]). In this study, the synovial fluid is modeled as Newtonian fluid.

In this paper, we have considered the situation where the tangential velocity is very small or zero and the load is high. This situation exists at the time of 'heel-strike' or 'toe-off', Paul [3] and in a mechanical bearing it can be related to the phenomenon of 'squeeze film lubrication'. In this mode of lubrication, the relative motion of the solids is due to the normal approach with no rolling or sliding movements of the solids. McCutchen [4] and Dowson et al. [5] have studied this situation in detail and put forward contradicting theories for the synovial joint lubrication under normal load and zero sliding velocity. Both of them have confirmed that the porosity of the cartilage play the crucial role in this situation.

In the year 1962, Dowson [6] unified the various attempts in generalizing the Reynolds Equation by considering the variation of fluid properties across as well as along the fluid film thickness by neglecting the slip effects at the bearing surfaces. Since then many researchers have studied the effects of viscosity variation in lubricated systems by considering Reynolds Equation [7-13].

McCutchen [4] emphasizes that the fluid in the joint cavity is due to 'wringing out' process from the cartilage matrix (Figure 2) and the fluid film is maintained hydrostatically rather than hydrodynamically. Thus, the load is carried mainly due to hydrostatic pressure of the fluid, which the cartilage weeps under loading. Mow et al. [14], Radin et al. [15] and Ling [16] have supported the mechanism, which is known as 'weeping lubrication'.

Walker et al. [17] have proposed an opposite theory for synovial joint lubrication for such a situation. According to their theory, which the authors have named as 'boosted lubrication', the mechanism heavily depends on the hyaluronate concentration in the synovial fluid and on the roughness character of the cartilage surface. They argue that when two cartilage surfaces are pressed against each other, nominal contact areas would be formed due to the roughness waves of the cartilage surface. The synovial fluid is trapped in these areas and the trapped pool of the fluid will contain high concentration of hyaluronate molecules, substance along with the base fluid will diffuse through the cartilage pores (Figure 3). This in turn increases the synovial fluid viscosity. A mathematical analysis, supporting this view has been also put forth (Dowson et al. [5]).

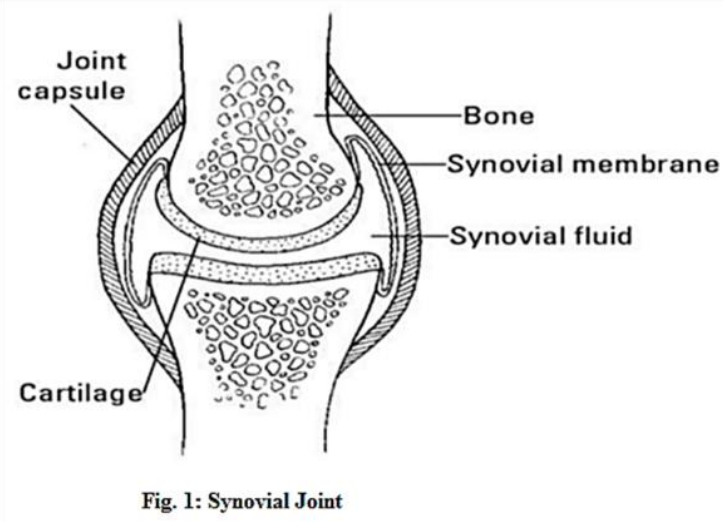

The system of synovial joint is a complex one and it is very difficult to account for all the factors simultaneously. Only a systematic study may be proved helpful in the study of such a system. Therefore, in this paper, a straightforward simple physical situation has been 
considered. A mathematical model for the squeezing porous surfaces lubricated with a Newtonian fluid has been suggested. A particular case, considering synovial fluid as Newtonian fluid with varying concentration of hyaluronic acid molecules has been studied in detail. Further, as the cartilage consists of porous material, it was suggested to apply the same methods as applicable in the study of mechanical porous bearing, to investigate the porous effect of the cartilage on the synovial joint lubrication. Therefore, we shall use Darcy's law in the porous matrix and an appropriate Reynolds equation in the fluid film region by taking permeability of the cartilage in the directions along and normal to the cartilage surface.

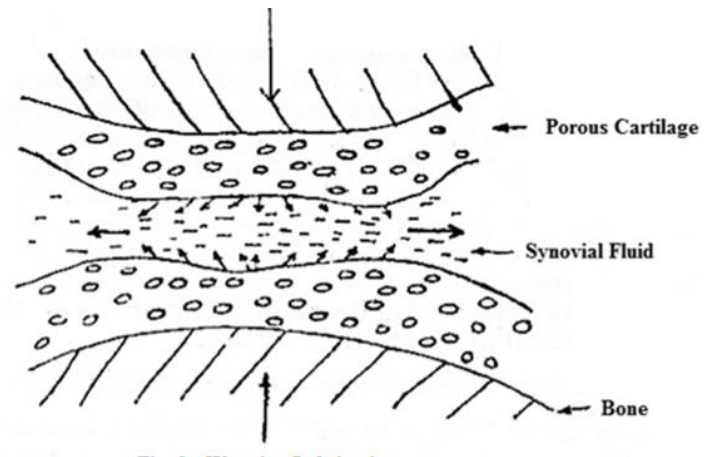

Fig. 2 : Weeping Lubrication

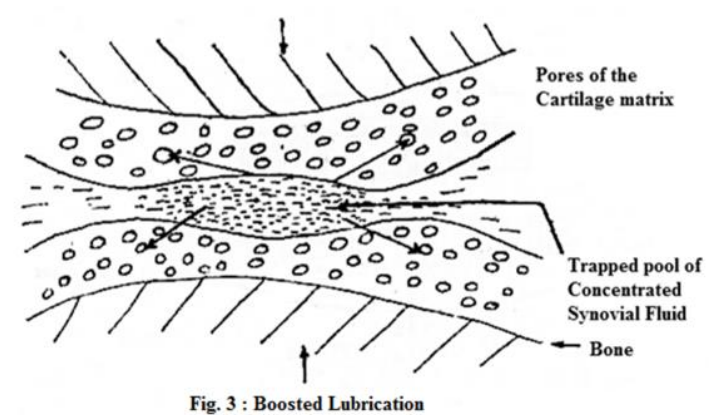

\section{MATHEMATICAL MODEL}

It has been pointed out by Walker et al. [18] that the load bearing area of the joints is small and so the two surfaces may be considered parallel under the high loading conditions. Also, it is suggested that the knee joint geometry can be approximated by two rectangular plates (Figure 4).

\subsection{Equation governing pressure in fluid film region}

Consider the geometrical model for knee joints as two porous rectangular discs, which are parallel and lubricated by Newtonian fluid. (Figure 4), the basic equation of motion for synovial fluid in the joint cavity can be written as:

$\frac{\partial}{\partial y}\left(\mu \frac{\partial u}{\partial y}\right)=\frac{\partial p}{\partial x}$

Where, $\mathrm{p}$ is the pressure and $\mu$ is the viscosity in the fluid film region, $\mathrm{u}$ is the fluid velocity along the $\mathrm{x}$-axis.

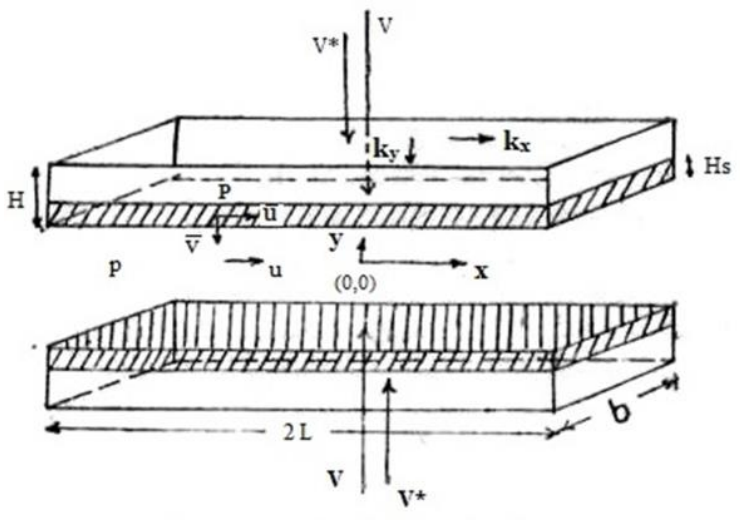

Fig. 4: Rectangular Model (Hum an Knee Joint)

The equation of continuity is

$$
\frac{\partial u}{\partial x}+\frac{\partial v}{\partial y}=0
$$

On integrating it from $\mathrm{y}=0$ to $\mathrm{h}$ and using symmetry of the system gives:

$$
[\mathrm{v}]_{\mathrm{y}=\mathrm{h}}=-\frac{\partial}{\partial \mathrm{x}} \int_{0}^{\mathrm{h}} \mathrm{udy}
$$

Where $[\mathrm{v}]_{\mathrm{y}=\mathrm{h}}=$ velocity in the $\mathrm{y}$ - direction at $\mathrm{y}=\mathrm{h}$ and includes the squeeze velocity $\mathrm{V}$, as well as the velocity $\overline{\mathrm{V}}$ of the fluid flowing from the cartilage to fluid film due to compression of the porous cartilage.

$$
[\mathrm{v}]_{\mathrm{y}=\mathrm{h}}=-\mathrm{V}-\overline{\mathrm{v}}
$$

and $\overline{\mathrm{V}}$ is to be determined by Darcy's law.

Solving equation (1) for $\mathrm{u}$ with the boundary conditions:

$$
\begin{array}{lll}
\mathrm{u}=0 & \text { at } & \mathrm{y}=\mathrm{h} \\
\frac{\partial \mathrm{u}}{\partial \mathrm{y}}=0 & \text { at } & \mathrm{y}=0
\end{array}
$$

We obtain the expression for $\mathrm{u}$ as follows:

$$
\mathrm{u}=\left(\frac{\partial \mathrm{p}}{\partial \mathrm{x}}\right) \int_{\mathrm{h}}^{\mathrm{y}} \frac{\mathrm{y}}{\mu} \mathrm{dy}
$$

Equations (2) and (3) give us the following differential equation, governing pressure in the fluid film region:

$$
\frac{\partial}{\partial x}\left(F \frac{\partial p}{\partial x}\right)=V+\bar{v}
$$

For $0 \leq \mathrm{x} \leq \mathrm{L}$, with the boundary conditions: 
$\frac{\partial \mathrm{p}}{\partial \mathrm{x}}=0$ at $\mathrm{x}=0$

$\mathrm{p}=0$ at $\mathrm{x}=\mathrm{L}$

(As the two regions, i.e. $\mathrm{x} \geq 0$ and $\mathrm{x} \leq 0$ are symmetrical, it is sufficient to consider only one region say $0 \leq x \leq L$ ),

Where

$$
\mathrm{F}=\int_{0}^{\mathrm{h}} \frac{\mathrm{y}^{2}}{\mu} \mathrm{dy}
$$

\subsection{Equation of pressure in the porous matrix of the cartilage}

Consider the physical situation of the flow behaviour in the cartilage matrix under squeeze film conditions (Figure 4 ), the equations of motion in the porous region ( $h \leq y \leq$ $h+H$ and $x \geq 0$ due to symmetry) can be written as:

$$
\begin{aligned}
& \overline{\mathrm{u}}=-\frac{\mathrm{k}_{\mathrm{x}}}{\mu_{0}} \frac{\partial \mathrm{p}}{\partial \mathrm{x}} \\
& \overline{\mathrm{v}}=\frac{\mathrm{k}_{\mathrm{y}}}{\mu_{0}}\left(\frac{\mathrm{P}-\mathrm{p}}{\mathrm{H}_{\mathrm{s}}}\right)
\end{aligned}
$$

Where, $\overline{\mathrm{u}}$ is the average velocity along $\mathrm{x}-$ axis, $\overline{\mathrm{v}}$ is the velocity of the fluid flowing from porous matrix towards fluid, $\mathrm{k}_{\mathrm{x}}$ and $\mathrm{k}_{\mathrm{y}}$ be the permeability in $\mathrm{x}$ and $\mathrm{y}$ directions respectively, $\mathrm{P}(\mathrm{x})$ is the mean pressure in the porous region with respect to the cartilage thickness $H, H_{s}$ is thickness of superficial tangential zone and $\mu_{0}$ is the base fluid viscosity.

Now, using the equation of continuity and integrating it for $\mathrm{y}$ in the limits $\mathrm{h} \leq \mathrm{y} \leq \mathrm{h}+\mathrm{H}$, we have:

$$
\frac{\partial}{\partial \mathrm{x}}\left(-\frac{\mathrm{Hk}_{\mathrm{x}}}{\mu_{0}} \frac{\partial \mathrm{p}}{\partial \mathrm{x}}\right)+\frac{\mathrm{k}_{\mathrm{y}}}{\mu_{0}}\left(\frac{\mathrm{P}-\mathrm{p}}{\mathrm{H}_{\mathrm{s}}}\right)=-\frac{\partial \mathrm{H}}{\partial \mathrm{t}}=\mathrm{V}^{*}
$$

Where $\mathrm{V}^{*}$ is the squeeze velocity of the cartilage surface at $y=h+H$ with respect to the surface $y=h$.

Thus, we have equation (4) as the appropriate Reynolds equation for the fluid film region and equation (8) as the one governing pressure in the porous region with the boundary conditions

$$
\begin{aligned}
& \frac{\partial p}{\partial x}=0 \text { at } x=0 \\
& p=P_{0} \text { at } x=L
\end{aligned}
$$

Where $\mathrm{P}_{0}$ is the hydrostatic pressure generated due to compression of the cartilage surface on loading.
These two equations (4) and (8) interact due to the presence of the factor $\overline{\mathrm{V}}$ and so, are dependent upon each other. To find the load capacity and squeeze time, one has to solve these equations simultaneously for $\mathrm{p}$ and $\mathrm{P}$ with the corresponding boundary conditions.

\section{VISCOSITY VARIATION}

The HA molecules are suspended in the base fluid and are mainly responsible for the Newtonian behavior of the synovial fluid.

$\mu=\mu_{0} \exp (\lambda C)$

Where $\lambda$ is a constant.

The concentration $\mathrm{C}$ is to be determined by an appropriate diffusion equation and depends upon the processes such as diffusion, biochemical reaction, trapping, consolidation etc., during the joint movements and it decreases, as the synovial joint gets diseased. A simple model is suggested here as follow (when the convection terms are negligible):

$\mathrm{D} \frac{\partial^{2} \mathrm{C}}{\partial \mathrm{y}^{2}}+\mathrm{M}=0$

Where $\mathrm{D}$ is the diffusion coefficient and $\mathrm{M}$ is the rate of increase or decrease of hyaluronate concentration. Taking account of the physical considerations and geometrical symmetry of the model, the boundary conditions can be prescribed as follows:

$$
\begin{aligned}
& \mathrm{D} \frac{\partial \mathrm{C}}{\partial \mathrm{y}}=0 \text { at } \mathrm{y}=0 \\
& \mathrm{C}=\mathrm{C}_{0} \quad \text { at } \mathrm{y}=\mathrm{h}
\end{aligned}
$$

Solving equation (10) with the above boundary conditions and substituting in (9) we obtain:

$$
\mu=\mu_{0} \exp \left\{\lambda C_{0}+\frac{\lambda M}{2 D}\left(h^{2}-y^{2}\right)\right\}
$$

\section{LOAD CAPACITY AND SQUEEZE TIME FOR THE HUMAN KNEE JOINT}

Now we solve the equations governing pressure for the case when the synovial fluid is assumed to behave as a Newtonian fluid with varying viscosity due to hyaluronate concentration. In that case, the equation (4) and (8) will be as follows:

$$
\begin{aligned}
& \frac{d}{d x}\left(F \frac{d p}{d x}\right)=-V-\frac{k_{y}}{\mu_{0}}\left(\frac{P-p}{H_{s}}\right) \\
& \frac{d}{d x}\left(\frac{H k_{x}}{\mu_{0}} \frac{d p}{d x}\right)=-V^{*}+\frac{k_{y}}{\mu_{0}}\left(\frac{P-p}{H_{s}}\right)
\end{aligned}
$$




\section{Available online at www.ijrat.org}

Where

$F=\int_{0}^{h} \frac{y^{2}}{\mu_{0} \exp \left\{\lambda C_{0}+\frac{\lambda M}{2 D}\left(h^{2}-y^{2}\right)\right\}} d y$

In non-dimensional form, it can be written as:

$\overline{\mathrm{F}}=\exp \left(-\lambda \mathrm{C}_{0}\right) \int_{0}^{1} \overline{\mathrm{y}}^{2} \exp \left\{\overline{\mathrm{M}}\left(\overline{\mathrm{y}}^{2}-1\right)\right\} \mathrm{d} \overline{\mathrm{y}}$

Where

$\overline{\mathrm{M}}=\frac{\lambda \mathrm{Mh}^{2}}{2 \mathrm{D}}, \overline{\mathrm{y}}=\frac{\mathrm{y}}{\mathrm{h}}, \overline{\mathrm{F}}=\frac{\mu_{0} \mathrm{~F}}{\mathrm{~h}^{3}}$

Adding equations (12) and (13), we get:

$\frac{\mathrm{d}}{\mathrm{dx}}\left(\mathrm{F} \frac{\mathrm{dp}}{\mathrm{dx}}+\frac{\mathrm{Hk}_{\mathrm{x}}}{\mu_{0}} \frac{\mathrm{dp}}{\mathrm{dx}}\right)=-\left(\mathrm{V}+\mathrm{V}^{*}\right)$

Which on integrating w. r. t. $\mathrm{x}$ and using the boundary conditions for $\mathrm{P}$ and $\mathrm{p}$, gives

$$
\mathrm{P}=\mathrm{P}_{0}+\frac{\mathrm{Hk}_{\mathrm{x}}}{\mu_{0}}\left[\frac{\left(\mathrm{V}+\mathrm{V}^{*}\right)}{2}\left(\mathrm{~L}^{2}-\mathrm{x}^{2}\right)-\mathrm{Fp}\right]
$$

Now substituting this expression for $\mathrm{P}$ in equation (12), we get the following differential equation governing pressure in the fluid film region:

$$
\begin{aligned}
\frac{\mathrm{d}^{2} \mathrm{p}}{\mathrm{dx}^{2}}-\beta^{2} \mathrm{p}=-\frac{1}{\mathrm{~F}}[\mathrm{~V}+ & \frac{\mathrm{k}_{\mathrm{y}}}{\mu_{0} \mathrm{H}_{\mathrm{s}}}\left\{\mathrm{P}_{0}\right. \\
& \left.\left.+\frac{\mu_{0}}{2 \mathrm{Hk}_{\mathrm{x}}}\left(\mathrm{V}+\mathrm{V}^{*}\right)\left(\mathrm{L}^{2}-\mathrm{x}^{2}\right)\right\}\right]
\end{aligned}
$$

Where

$$
\beta^{2}=\frac{\mathrm{k}_{\mathrm{y}}}{\mathrm{H}_{\mathrm{s}}}\left(\frac{1}{\mathrm{Hk}_{\mathrm{x}}}+\frac{1}{\mu_{0} \mathrm{~F}}\right)
$$

Solving equation (17) with the corresponding boundary conditions for $p$, the pressure in the fluid film region is determined as follows:

$$
\begin{aligned}
& \mathrm{p}=\frac{\mu_{0}}{\left(\mu_{0} \mathrm{~F}+\mathrm{Hk}_{\mathrm{x}}\right)}\left[\frac{\left(\mathrm{V}+\mathrm{V}^{*}\right)}{2}\left(\mathrm{~L}^{2}-\mathrm{x}^{2}\right)\right. \\
& \left.+\frac{1}{\beta^{2}}\left(1-\frac{\cosh (\beta \mathrm{x})}{\cosh (\beta \mathrm{L})}\right)\left\{\frac{\mathrm{Hk}}{\mu_{0}}\left(\frac{\mathrm{V}}{\mathrm{F}}+\beta^{2} \mathrm{P}_{0}\right)-\mathrm{V}^{*}\right\}\right]
\end{aligned}
$$

Now the load capacity for the synovial joint is given by:

$$
\mathrm{W}=2 \mathrm{~b} \int_{0}^{\mathrm{L}} \mathrm{p} d \mathrm{x}
$$

Thus, we have the non-dimensional form for the load capacity as follows:

$$
\begin{aligned}
\overline{\mathrm{W}} & =\frac{\mathrm{Wh}^{3}}{2 \mu_{0} \mathrm{bVL}^{3}} \\
& =\frac{\overline{\mathrm{F}}+3 \mathrm{f} \overline{\mathrm{k}}_{\mathrm{x}}}{3 \overline{\mathrm{F}}\left(\overline{\mathrm{F}}+\overline{\mathrm{k}}_{\mathrm{x}}\right)}+\frac{1-3 \mathrm{f}}{3\left(\overline{\mathrm{F}}+\overline{\mathrm{k}}_{\mathrm{x}}\right)} \overline{\mathrm{V}}^{*}+\frac{\mathrm{f} \overline{\mathrm{k}}_{\mathrm{y}}}{\overline{\mathrm{F}}} \overline{\mathrm{P}}_{0}
\end{aligned}
$$

Where

$$
\begin{aligned}
& \mathrm{f}=\frac{1}{\beta^{2} \mathrm{~L}^{2}}\left(1-\frac{\tanh (\beta \mathrm{L})}{\beta \mathrm{L}}\right), \overline{\mathrm{F}}=\frac{\mu_{0} \mathrm{~F}}{\mathrm{~h}^{3}}, \overline{\mathrm{k}}_{\mathrm{x}}=\frac{\mathrm{Hk}_{\mathrm{x}}}{\mathrm{h}^{3}}, \\
& \overline{\mathrm{k}}_{\mathrm{y}}=\frac{\mathrm{L}^{2} \mathrm{k}_{\mathrm{y}}}{\mathrm{H}_{\mathrm{s}} \mathrm{h}^{3}}, \overline{\mathrm{V}}^{*}=\frac{\mathrm{V}^{*}}{\mathrm{~V}}, \overline{\mathrm{P}}_{0}=\frac{\mathrm{P}_{0} \mathrm{~h}^{3}}{\mu_{0} \mathrm{VL}^{3}}, \\
& \beta^{2} \mathrm{~L}^{2}=\overline{\mathrm{k}}_{\mathrm{y}}\left(\frac{1}{\overline{\mathrm{F}}}+\frac{1}{\overline{\mathrm{k}}_{\mathrm{x}}}\right)
\end{aligned}
$$

From equation (20) the time of squeezing can be obtained by substituting $\mathrm{V}=-\mathrm{dh} / \mathrm{dt}$ and then integrating with respect to $h$ from $h=h_{i}$ (initial position) to $h=h_{f}$ (final position). Thus, the time of squeezing for the cartilage surface to reach the position $\mathrm{h}=\mathrm{h}_{\mathrm{f}}$ from an initial position $\mathrm{h}=\mathrm{h}_{\mathrm{i}}$ is given by:

$$
\mathrm{t}=\frac{2 \mu_{0} \mathrm{bL}^{3}}{\mathrm{Wh}_{\mathrm{f}}^{2}} \overline{\mathrm{t}}
$$

Where

$$
\begin{gathered}
\overline{\mathrm{h}}=\frac{\mathrm{h}}{\mathrm{h}_{\mathrm{f}}}, \overline{\mathrm{h}}_{\mathrm{i}}=\frac{\mathrm{h}_{\mathrm{i}}}{\mathrm{h}_{\mathrm{f}}}, \overline{\mathrm{F}}=\frac{\mu_{0} \mathrm{~F}}{\mathrm{~h}_{\mathrm{f}}^{3}}, \overline{\mathrm{k}}_{\mathrm{x}}=\frac{\mathrm{Hk}_{\mathrm{x}}}{\mathrm{h}_{\mathrm{f}}^{3}}, \overline{\mathrm{k}}_{\mathrm{y}}=\frac{\mathrm{L}^{2} \mathrm{k}_{\mathrm{y}}}{\mathrm{H}_{\mathrm{s}} \mathrm{h}_{\mathrm{f}}^{3}}, \\
\mathrm{~V}^{\prime}=\frac{2 \mu_{0} \mathrm{bV}^{*} \mathrm{~L}^{3}}{\mathrm{Wh}_{\mathrm{f}}^{3}}, \mathrm{P}_{0}^{\prime}=\frac{2 \mathrm{bLP} \mathrm{P}_{0}}{\mathrm{~W}}, \\
\overline{\mathrm{t}}=\int_{1}^{\overline{\mathrm{h}}_{\mathrm{i}}}\left(\overline{\mathrm{F}}+3 \overline{\mathrm{k}}_{\mathrm{x}} \mathrm{f}\right) \\
\left\{\frac{\mathrm{dh}}{3 \overline{\mathrm{F}}\left(\overline{\mathrm{F}}+\overline{\mathrm{k}}_{\mathrm{x}}\right)-\overline{\mathrm{F}}(1-3 \mathrm{f}) \mathrm{V}^{\prime}-3 \mathrm{f} \overline{\mathrm{k}}_{\mathrm{y}}\left(\overline{\mathrm{F}}+\overline{\mathrm{k}}_{\mathrm{x}}\right) \mathrm{P}_{0}^{\prime}}\right\}
\end{gathered}
$$

and $\bar{M}$ appearing in $\bar{F}$ will be defined as $\bar{M}=\frac{\lambda \mathrm{Mh}_{\mathrm{f}}^{2}}{2 \mathrm{D}}$ 


\section{Available online at www.ijrat.org}

The equation (20) and (21) has been plotted for different values of permeabilities $\left(\overline{\mathrm{k}}_{\mathrm{x}}\right.$ and $\left.\overline{\mathrm{k}}_{\mathrm{y}}\right)$ and for the various sets of concentration parameters in Figures 5 to 8 . It can be noted that the load capacity and time of squeeze decrease as $\overline{\mathrm{k}}_{\mathrm{x}}$ increases and so higher permeability in the tangential direction will have unfavorable effect on the synovial joint performance. The increased concentration enhances the load bearing capacity of the joint as well as the time of squeeze (Figures 6 and 8).

\section{CONCLUSION}

In this work the effect of cartilage porosity and viscosity variation due to change in hyalurnate concentration has been studied. The permeability effects have been accounted by considering the cartilage parmeabilities in the directions along as well as normal to the cartilage surface. It has been shown that the permeability in the normal direction has a favorable effect on the load capacity as well as on the squeeze time, results are in line with those obtained by Chandra [19].

The effect of viscosity variation due to the change in hyaluronate concentration has also considered. It has been observed that the increase in the concentration parameters enhances the load capacity of the joint and delays the time of squeezing. Moreover, the effect of concentration variation is more pronounced. Therefore, it can be concluded that concentration variation of hyaluronic acid molecules is more important and so the process of consolidation and enrichment is responsible for the better performance of the synovial joint. Thus, the analysis supports the concept of 'Boosted Lubrication' as suggested by Dowson et al. [5] under the conditions of high load and no tangential movements of the cartilage surfaces.

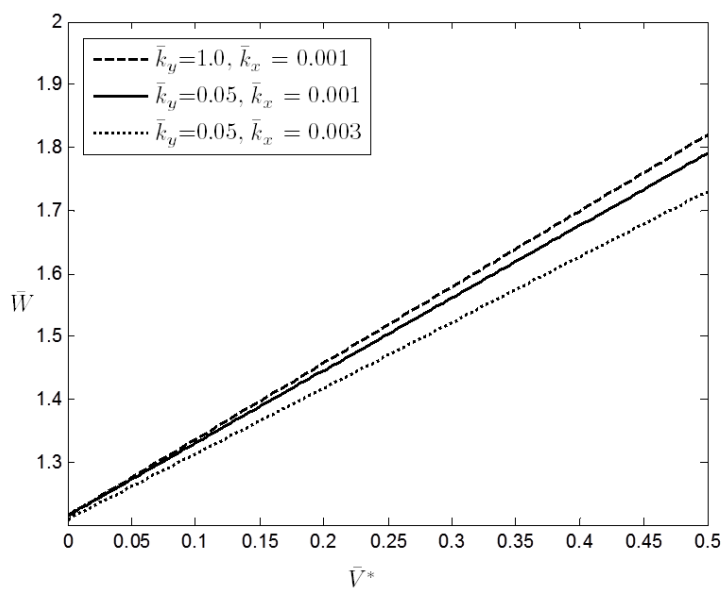

Fig. 5: Variation of $\overline{\mathrm{W}}$ with $\overline{\mathrm{V}}^{*}$ for different values of $\overline{\mathrm{k}}_{\mathrm{x}}, \overline{\mathrm{k}}_{\mathrm{y}}$ and $\overline{\mathrm{P}}_{0}=0.2, \lambda \mathrm{C}_{0}=0.1$,

$$
\overline{\mathrm{M}}=0.25
$$

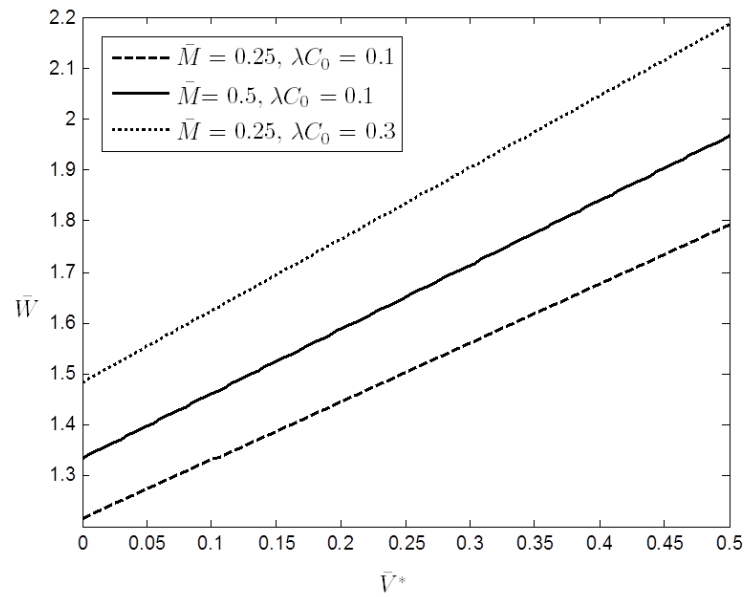

Fig. 6: Variation of $\overline{\mathrm{W}}$ with $\overline{\mathrm{V}}^{*}$ for different values of $\lambda \mathrm{C}_{0}$ and $\overline{\mathrm{M}}$ for $\overline{\mathrm{P}}_{0}=0.2, \overline{\mathrm{k}}_{\mathrm{x}}=0.001$,

$$
\overline{\mathrm{k}}_{\mathrm{y}}=0.05
$$

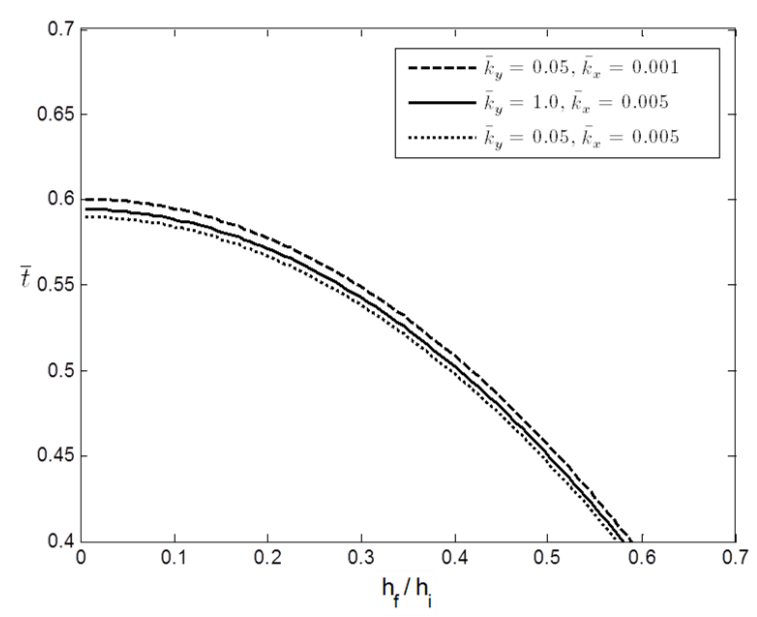

Fig. 7: Variation of $\overline{\mathrm{t}}$ with $\mathrm{h}_{\mathrm{f}} / \mathrm{h}_{\mathrm{i}}$ for different values of $\overline{\mathrm{k}}_{\mathrm{x}}$ and $\overline{\mathrm{k}}_{\mathrm{y}}$ for $\lambda \mathrm{C}_{0}=0.1, \overline{\mathrm{M}}=0.1$,

$$
\mathrm{V}^{\prime}=0.1, \mathrm{P}_{0}^{\prime}=0.1
$$

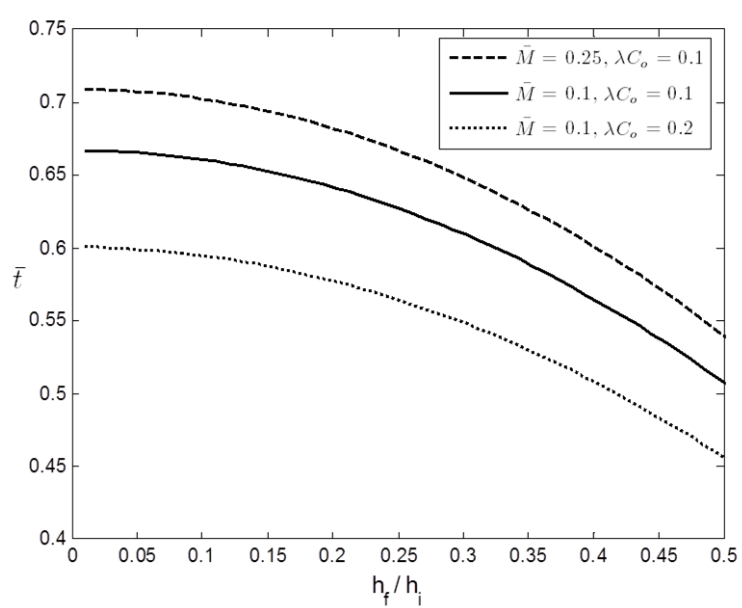

Fig. 8: Variation of $\bar{t}$ with $h_{f} / h_{i}$ for different values of $\lambda \mathrm{C}_{0}$ and $\overline{\mathrm{M}}$ for $\mathrm{V}^{\prime}=0.1, \mathrm{P}_{0}^{\prime}=0.1$

$$
\overline{\mathrm{k}}_{\mathrm{x}}=0.001, \overline{\mathrm{k}}_{\mathrm{y}}=0.05
$$




\section{Acknowledgment}

The author would like to thank Prof J. B. Shukla, Indian Institute of Technology, Kanpur for his valuable suggestions and encouragement during the completion of this study.

\section{REFERENCES}

[1] Cooke, A. F.; Dowson, D.; and Wright, V. (1978): The rheology of synovial fluid and some potential synthetic lubricants for degenerate synovial joints. Engineering in Medicine, 7(2), pp. 66-72.

[2] Dowson, D. and Jin, Zhong-Min (1986): Microelastohydrodynamic lubrication of synovial joints. Engineering in Medicine, 15(2), pp. 63-65.

[3] Paul, J. P. (1966): Force transmitted by joints in the human body. Proceedings of the Institution of Mechanical Engineers, 181 (pt 3J), Paper No. 8, pp. $8-15$.

[4] McCutchen, C. W. (1962): The frictional properties of animal joints. Wear, 5(1), pp. 1-17.

[5] Dowson, D.; Unsworth , A. and Wright, V.(1970): Analysis of 'Boosted Lubrication' in human joints. Journal of Mechanical Engineering Science, 12(5), pp. 364-369.

[6] Dowson, D. (1962): A generalized Reynolds equation for fluid film lubrication. International Journal of Mechanical Sciences, 4(2), pp. 159-170.

[7] Shukla, J.B. (1964): Theory for the squeeze film for power law lubricants. Transactions of the ASME, Paper No. 64-lub-4.

[8] Shukla, J.B.; Prasad K.R. and Chandra; Peeyush (1982): Effects of consistency variation of power law lubricants in squeeze films. Wear, 76(3), pp. 299319.

[9] Tyagi, A. P.; Saxena, Arti and Shekhar, K. (2010): Mathematical modeling of normal human knee joint function under highly loaded conditions: One layer model: Effects of HA molecules squeezing (Symmetrical Case). International Journal of Applied Mathematics and Applications, 2(2), pp. 183-195.

[10] Tyagi, A. P.; Saxena, Arti and Shekhar, K. (2010): Mathematical modeling of normal human knee joint function under highly loaded conditions: One layer model: Effects of HA molecules squeezing (NonSymmetrical Case). International Journal of Mathematics and Applied Statistics, 1(2), pp. 127138.

[11]Rao, R. R.; Gouthami, K.; Kumar, J.V. (2013): Effects of velocity-slip and viscosity variation in squeeze film lubrication of two circular plates, Tribology in Industry, 35(1), pp. 51-60.

[12] Kumar, J. V.; Rao, R. R. (2015): Effects of surface roughness in squeeze film lubrication of two parallel plates, Tribology in Industry, 37(2), pp. 161-169.

[13] Shekhar, Kapil; Saxena, Arti; Tyagi, A. P. (2016): Mathematical modeling of diseased human knee joint under jumping condition", Proceedings of the $10^{\text {th }}$ INDIACom, IEEE Conference ID: 37465, pp. 55455549, BVICAM (New Delhi).
[14] Mow, Maurice C. and Ling, Frederick F. (1969): On weeping lubrication theory. ZAMP, 20 (2), pp. 156,

[15] Radin, E. L.; Paul, I. L. and Pollock, D. (1970): Animal joint behaviour under excessive loading”, Nature, 226, pp. 554-555.

[16] Ling, F. F. (1974): A new model of articular cartilage in human joints. Journal of Lubrication Technology (ASME), 96 (3), pp. 449-454.

[17] Walker, P. S.; Dowson, D.; Longfield, M. D. and Wright, V. (1968): Boosted lubrication in synovial joints by fluid entrapment and enrichment. Ann. Rheum. Dis., 27, pp. 512-520.

[18] Walker, P. S.; Hajek, J. V. (1972): The load bearing area in the knee joint. Journal of Biomechanics, 5(6), pp. 581-584.

[19] Chandra, Peeyush (1979): Effect of cartilage porosity on synovial joint lubrication. National Academy of Sciences (India), pp. 265-279. 